\title{
Corrigendum
}

\section{Selenium Effects on cAMP Metabolism in Hepatoma Cells and Normal Liver Cells}

In the paper "Different Effects of Selenium on Cyclic AMP Metabolism in Hepatoma Cells and Normal Liver Cells," by Shu-Yu Yu and Li-Ming Wang, Biological Trace Element Research, 5, 9-16 (1983), the line drawings in Figs. 1 and 2 were exchanged. The corrected figures and legends are given below.

HEPATOMA
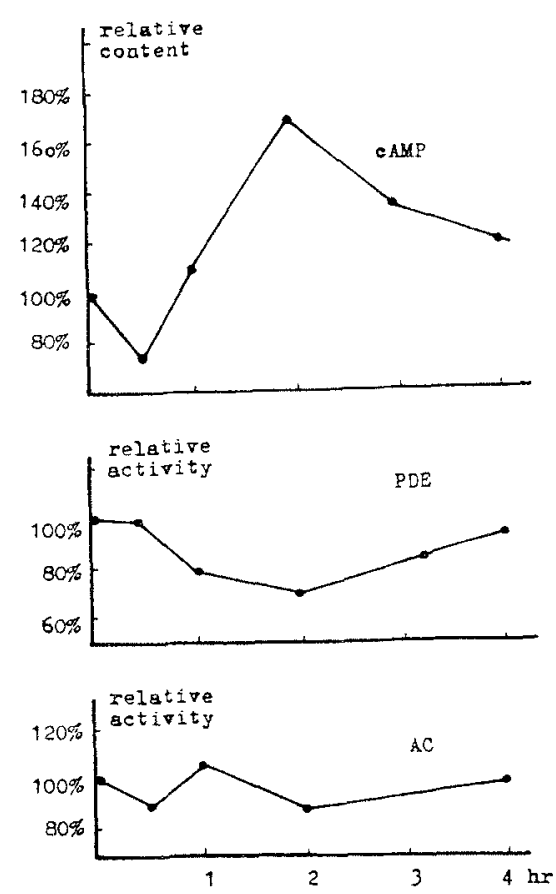

HOST LIVER
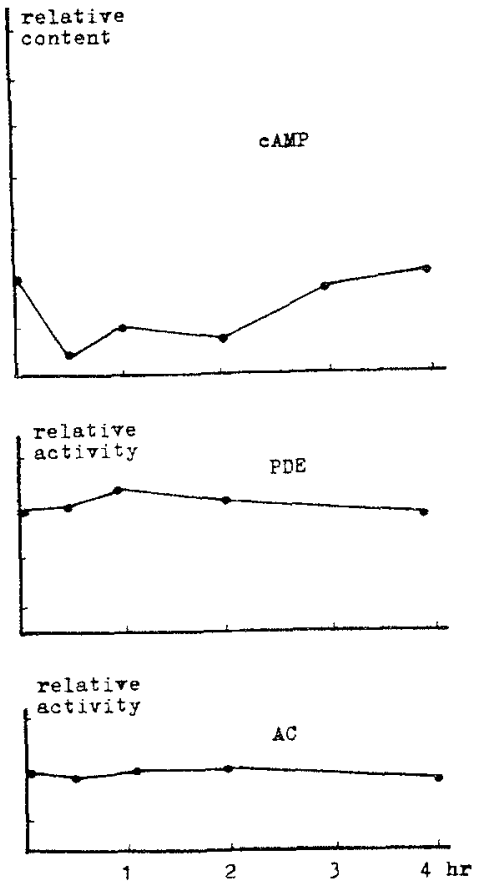

Fig. 1. Time course study on the effect of $\mathrm{Na}_{2} \mathrm{SeO}_{3}(2 \mathrm{mg} / \mathrm{kg} \mathrm{sc})$ on cAMP metabolism. The results are expressed by $\%$ compared with untreated group, the data for which have been shown in Table 1 . 

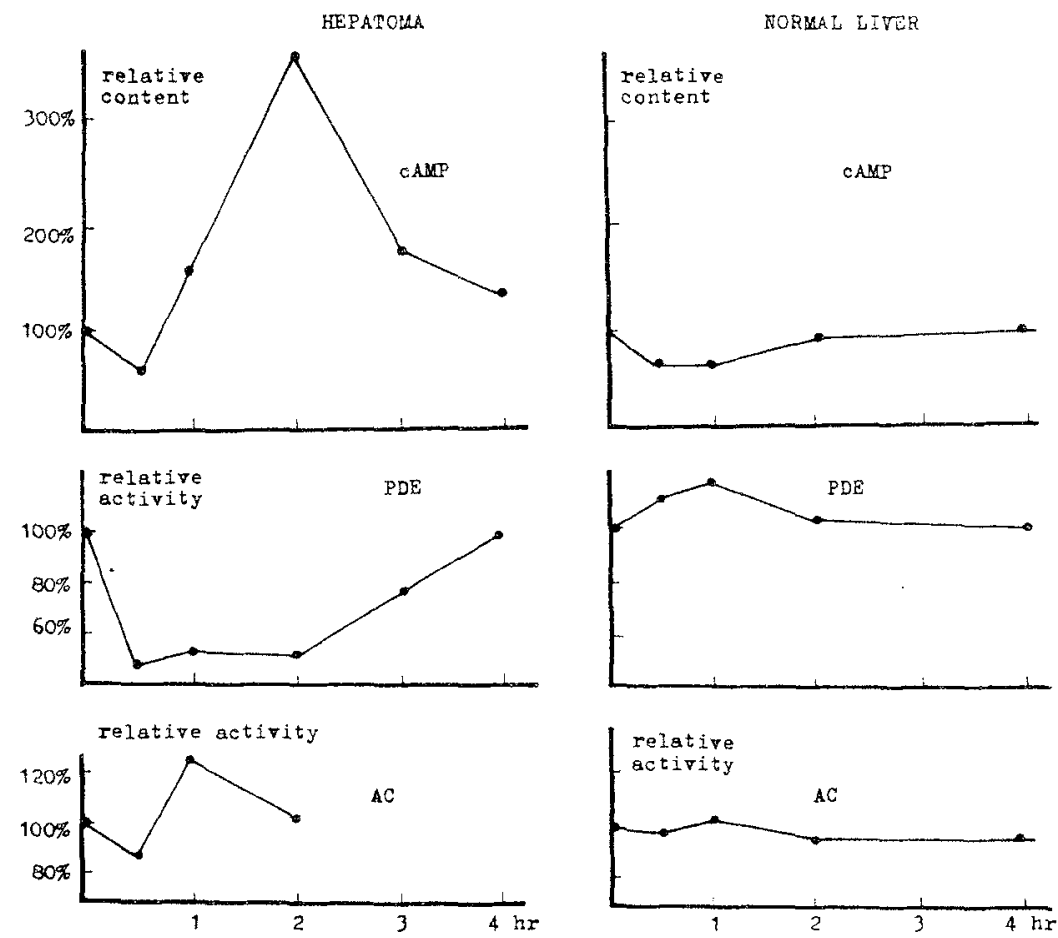

Fig. 2. Time course study on effect of $\mathrm{Na}_{2} \mathrm{SeO}_{3}(1 \mathrm{mg} / \mathrm{kg}$ ip) on CAMP metabolism. The results are expressed by \% compared with untreated group. the data of which have been shown in Table 1. 